\title{
Next steps in Newborn Intensive Care Unit design and developmental care
}

\author{
Robert D. White (D) ${ }^{1}$ \\ ○ Springer Nature America, Inc. 2020
}

The Newborn Intensive Care Unit (NICU) environment of care has changed dramatically in the years since the first Recommended Standards were published in 1999. At that time NICUs were bright, noisy, crowded spaces where infections were common for babies, post-traumatic stress disorder was common for parents, and burnout was common for the staff. Although there was extensive literature on the importance of parental presence for newborns, parents were largely excluded from contact with their critically ill infant. Daylighting was rare, circadian rhythm non-existent, and ergonomics still largely ignored.

The illnesses we treat have changed as well. Erythroblastosis fetalis, meconium aspiration pneumonia, early-onset Group B Streptococcal infection, and patent ductus arteriosus requiring surgical ligation are far less common now than they were in the 1990s. Neonatal abstinence syndrome, retinopathy of prematurity requiring surgical intervention, and prematurity itself may be substantially less common within the lifespan of a NICU being planned today.

How should we design our NICUs to address and anticipate these changes? The development of prior Recommended Standards has proven to be a powerful tool for change in the basic structural requirements so that the needs of babies, families, and caregivers can be met. But even the revised standards published in this supplement are the minimum standards, and optimal care requires additional structural considerations as well as enhancement of many operational practices. The articles in this supplement that accompany the Recommended Standards are intended to help those planning new construction or major renovation for their NICU to accomplish optimal care upon occupancy of the new facility, as well as flexibility for the changes sure to come for our profession in the next generation.

Funding This article is published as part of a supplement sponsored by Philips.

\section{Compliance with ethical standards}

Conflict of interest RDW has received consulting fees from Philips HealthTech, owns equity in Mednax, and received lecture fees from $\mathrm{P}+\mathrm{G}$ (Pampers). The author also holds patents for two products (not for sale).

Publisher's note Springer Nature remains neutral with regard to jurisdictional claims in published maps and institutional affiliations.
Robert D. White

Robert_White@mednax.com

1 Regional Newborn Program, Beacon Children's Hospital, South Bend, IN, USA 